\title{
Investigation of Heat Transfer Enhancement in the Refrigerator Freezer via Utilizing Elliptical-Shaped Scars
}

\author{
Mustafa Ahmed Abdulhussain ${ }^{1, *}$ \\ Department of Mechanical Engineering, University of Technology, Baghdad, Iraq
}

\section{ARTICLE INFO}

Received 19 March 2020

Received in revised form 18 May 2020

Accepted 23 May 2020

Available online 31 May 2020

\section{Article history:}

\section{ABSTRACT}

The high energy demand in addition to the negative global warming potential effects that the Refrigeration and Airconditioning equipment are highly contributing lead to their progressive amendment via the utilization of fluid flow different configurations control surfaces to achieve a higher freezing efficiency and reduce the power consumption. Several Researches are conducted on the natural and forced convection evaporator freezer geometry modification by either of modifying of the compartment walls or the additional insertion of supplementary flow control surfaces. Due to the low rate of heat transfer inside the natural convection devices working under hot climate conditions lead to the adoption of the specified technique to overcome this problem. In this paper, the insertion of elliptical shape scars of equal dimensions distributed linearly on the upper and lower inner surfaces of the refrigerator freezer working under natural convection principle is conducted numerically and tested experimentally to determine the velocity and temperature of the air taking into consideration the effect of increasing the scar height and reducing the gaps between them. The freezer cooling method is modified to the forced convection form by using an AC axial small fan that rotates at the rear wall at a constant speed of 1500 revolutions per minute. With implementing the shear stress transport turbulence model in the commercial ANSYS CFX software for a transient time of $(15,20 \& 25)$ seconds are considered. The simulation results showed that the increased scars height from (0.5-1.0) centimeters has a positive effect on increasing of the air rotation by a maximum of (80 percent) in comparison to the improvement in convection heat transfer for the area with a variable rate achieving a maximum value of (12 per cent) noticing that the upper freezer scars distribution has achieved a better subcooling effect rather than the lower surface. Better convergence is reached with test results ranging from (7-14) \%, respectively.

Keywords:

Refrigerator freezer; elliptical scars; heat transfer enhancement

\section{Introduction}

A greater attention concerning the natural heat transfer operating devices has been focused through the recent years [1] since the natural convection heat exchange devices lacks high cooling

\footnotetext{
* Corresponding author.

E-mail address: mustafa_ahmed2018@yahoo.com (Mustafa Ahmed Abdulhussain)
}

https://doi.org/10.37934/cfdl.12.5.6081 
efficiency at high ambient air temperature $\left(>40^{\circ} \mathrm{C}\right)$ and under high demanded cooling load such as the chest freezer and huge volume Refrigerator Freezer [2], the need for performance improvement and reducing the power consumption via several modifications are considered the main priority target for the researchers for this kind of Refrigeration equipment due to their simple operating principle.

The house hold vapor compression Refrigeration devices are classified into two major types that are the natural and the forced convectional heat transfer operation [3]. The major difference between them is that the natural type requires a greater flowing amount of charged Refrigerant in addition to the adequate size of piping as it is preferred for small and moderate compact sizes. An additional deficiency parameter is the continuous manual removing frost accumulation at the freezer compartment periodically. On the other hand, the forced convection type devices require less charge of Refrigerant in addition to their high rate of heat exchange at hot climate conditions, but requires an intensive design requirements such as the implementation of the Refrigerant ejector control tool and the frosting heating element in addition to the high rate of power consumption as the compressor operating time is relatively high until reaching the desired freezing temperature for the high cooling load demand. This led to the additional research efforts to improve the natural convectional devices efficiency via the application of several techniques so as to raise their cooling load efficiency. The fluid flow geometrical control tools that have greatly affects the heat transfer rate including the dimples, fins, scars, riblets, winglets, baffles in addition to the curved knobs as their contribution is accomplished in reducing flow drag and retaining flow energy [4,5] as these techniques are commonly used in hot-flow regions and heat exchange systems in the cooling passages [6].

Several studies are conducted on the fluid flow and the heat transfer enhancement on multivolume flow modified shapes, the understanding of the aerodynamic flow behavior regarding the above-mentioned flow controls in the turbulent boundary layer region is conducted by van Campenhout et al., [7] In a low-speed wind tunnel experimentally using the particle image tracking technique on spherical passive dimple surfaces distributed in the stream and in span directions in different distribution patterns in order to determine the drag power, airflow speed, pressure and temperature. Due to the interaction of the dimple flow affected regimes, the results indicated a high oscillation in the span wise direction, leading to the sequential drag reduction.

Luo et al., [8] studied the heat transfer improvement rate on a rectangular shaped duct was studied numerically using pin fins with the addition of passive flow dimples with various crosssectional shapes including circular and elliptical forms (stream and span) and flow patterns with variable Reynolds number between $(50,000-100,000)$ showed a great improvement in the heat transfer rate due to the improved vorticity flow within the fins.

Awasarmol and Pise [9] investigated experimentally the application of the inclined fins on the natural convection heat transfer process in a flat plate with different distribution pattern including the linear, the zigzag and the staggered for both solid and perforated types with the variation of their inclination angle from $\left(0-90^{\circ}\right)$ taking into consideration that the perforated fins are drilled with several sizes of holes ranging between $(6-12 \mathrm{~mm})$, respectively. The entire combination is subjected to a heating variable rate via an electric heater that is located between the vertically arrayed finned surfaces with the adoption of the inclination angle change sequence to 0,30,45,60 and 90 degrees. The testing results showed that the perforated zigzag fins with vertical inclination angle has achieved the maximum convection heat transfer coefficient for a constant heating rate value. In addition, the heat transfer coefficient has been highly improved as the perforated holes size becomes higher than $(8 \mathrm{~mm})$ especially for higher applied heating load. 
Yasin and Ghanim [10] introduced numerically and experimentally the adoption of circle, circular and triangular passive flow controls (dimples) in the heat exchanger flow pipes, the numerical solution is obtained using the SST turbulence model in the FLUENT software to determine pressure drop and coefficient of convection heat transfer. As found from the numerical solution, the triangular form dimples had the best heat transfer effect other than the circular and simple forms, while the circular shape of dimples assigned the largest Nusselt number and pressure decrease from tests.

The condensation rate and the pressure drop of the $\mathrm{R}(134 \mathrm{a})$ flow in the annulus double pipe heat exchanger tubes with passive controls, without which Aronnrat and Wongwises [11] was experimentally investigated taking into account the effect of the flow-induced boundary conditions on the heat transfer coefficient and the pressure drop, the dimpled surface tubes decreased the Nusselt number by (1.3-1.4) other than the smooth tubes, whereas the pressure drop for the dimpled flow is significantly greater.

The realizable K- $\varepsilon$ turbulence model use in the passive (convex) dimpled flow simulation is carried out by Nazari et al., [12] using staggered and circular pattern dimples spread over flat plate taking into account the influence of the depth of the dimple with the variation of the flow Reynolds number from $(50,000-100,000)$, respectively. All of the chosen dimple patterns decreased the Nusselt flow level, but the increased dimple depth caused considerably more pressure-loss and lack of heat transfer rate due to the increased recirculated flow inside the dimple holes.

The installation of active flow controls on the fin's surfaces in the fin and tube heat exchanger is carried out numerically by Wu et al., [13] to test heat transfer enrichment for low-speed steady airflow range from (1-1.3) $\mathrm{m} / \mathrm{sec}$ with the adoption of the standard $\mathrm{K}-\varepsilon$ model. The results indicated that the active (concave) dimples generate a streamlined flow of the ponytail which contributes to the increase in the heat transfer rate.

The insertion of additional finned high conductivity material thin plates of constant small thickness within the natural convection Refrigerator freezer is performed by Zhao et al., [14] numerically and experimentally at different positions within the M-package shape of food specimen. Taking the laminar flow conditions for the numerical solution. The plates installation at the bottom or both of bottom and top of the food specimen has significantly improved the freezing time period.

The enhancement of the heat transfer inside the refrigerator freezer plays an important role in the power consumption of the system and in increasing the cooling efficiency when operating under hot conditions, Nikbay et al., [15] performed a transient simulation analysis inside a domestic refrigerator freezer for both laminar and turbulent flow behaviour and heat transfer efficiency Laboratory studies using the particle velocity measurement method support the findings; they measured the energy consumption adjustments for different freezer packages and found that the energy consumption decreases with the difference in temperature between the freezer packages.

Laguerre et al., [16] carries out numerical simulation aided by fluid flow and heat transfer experiments inside the normal type of non-ventilated domestic refrigerator, assuming steady evaporator temperature and circulating laminar airflow in the presence or absence of radiation heat transfer. The results showed a good agreement with experiments.

With the aid of digital thermocouples, the circulating air inside the freezer compartment of the non-frost empty refrigerator calculation is carried out by Lacerda et al., [17] using the particle picture velocity process., The measurement checks are carried out from the start of the refrigerator until the healthy state is reached. The results showed that lower temperature of the walls contributes to lower temperature of the compartment flow region.

Several researchers performed the calculation of the convection heat transfer coefficient for multi-shaped evaporator compartments in the domestic refrigerators, Lee et al., [18] investigated experimentally the heat transfer coefficient for three different kinds of evaporators including the in- 
line discrete, the staggered continuous and the spine linear flat plate fin and tube types. They developed heat transfer correlations for each evaporator type with respect to the flow Reynolds and the PrandtI numbers that have achieved a high accuracy with experiments. The spine type evaporator achieved the highest rate of heat transfer rate under the non-frost compartment condition.

The implementation of the rectangular and triangular cross-section air shufflers as a vortex generation surfaces at outlet of the forced convection Refrigerator freezer is handled by Çerezci et al., [19] numerically seeking for the optimum dimensions that achieves the best heat transfer enhancement for the turbulent flow conditions inside the Freezer cabinet. The adoption of the standard $K-\varepsilon$ turbulence model for the numerical simulation. With the application of a hot food specimen within the freezer, the triangular shape air shuffler provided a higher rate of generated heat flux for the specimen and better heat transfer within the flow field due to their highly secondary flow waves generation.

An alternative vortex generation technique is implemented by Sommers and Jacobi [20] via the installation of an arrayed delta wing tip to the finned forced convection heat exchanger within the frosting type freezer experimentally in order to minimize the boundary layer formation and further improvement in the heat transfer rate. With the variation of the freezer air Reynolds number from (500-1300), the thermal resistance of the heat exchanger is reduced within (35-42\%) and a general enhancement in the convection heat transfer within $\left(20 \mathrm{~W} / \mathrm{m}^{2} \mathrm{~K}\right)$ for the specified air flow speed.

A comparison between the plate and the spiral fins shape of evaporators utilizing in the refrigerator freezer is performed by Lee et al., [21] experimentally with different tubes rows and columns configurations. The results showed an equal amount of cooling speed for each type but the spiral type utilizing have achieved lower power consumption and higher cooling capacity.

An addition modification to the no-frost freezer compartment is performed by Celik et al., [22] numerically with the application of the v-grooved tube shape within the finned type two-phase flow heat exchange evaporator. With the application of the conservation of mass and momentum equation for both of the phases flow in the MATLAB software considering constant grooved shape characteristics including the groove angle in addition to its depth and the tube thickness, the grooved tubing shape achieved an enhanced heat exchange effectiveness and better coefficient of performance for the entire refrigeration cycle.

Liu et al., [23] established a new approach so-called the reverse heat loss method for the evaluation of the heat transfer coefficient in the freezer compartment with the insertion of a sealing gaskets. The application of a variable heat flux in the compartment with the installation of a rear axial fan introduced a great increase in the heat leakage of the evaporator.

From all above surveyed literature, it obvious that the performed researches concentrated on the positive and negative control surfaces in either natural or forced convection heat transfer cooling devices without paying attention to the portioned narrowing of the freezer cabinet using the extended surfaces of relatively thick scars that are distributed in different patterns, this research gap with the implementation of the natural convection operating freezer modification to the forced convectional type serve to the low modification cost of the proposed technique in addition to the reducing the operational time for the Refrigeration cycle that contribute in lower power consumption which reflects the importance of investigation the proposed modifications as a major study concern in this field.

The current research aims at exploring the use of the active flow control elliptical forms scars on the upper and lower surfaces of the closed enclosure within the household refrigerator's non-frozen plate natural convection style evaporator freezer.

The enhancement of the heat transfer rate will be investigated numerically and experimentally validated by transforming the model of evaporator from normal to forced convection one with the 
assistance of an axial flow fan mounted at the Back of the freezer compartment, taking into account the linear pattern distribution of the active control device (elliptical scars) with variable distance in the direction of the stream of the freezer compartment in addition to the height variance of the surfaces. With the use of the SST turbulence model in the ANSYS CFX software considered transient case simulation with the implementation of initial temperatures for the system as boundary conditions for the measured walls. Since the ejector freezer cabinet non-frosting refrigerators demands intensive design parameters such as the condenser configuration in addition to the defrosting technique, this called for alternative simple and efficient methods including the combining of both of the active thermal enhancement control surfaces with the application of the forced convectional flow for the naturally heat transfer cooling freezer compartment. This method will serve two targets, first the rotational fan will prevent the frosting accumulation, and second the active control surface of small dimensions will assist in the formation of wavy flow regions that are enclosed between each scar which will further improve the flow turbulences within the freezer compartment and will improve the conductance rate of heat transfer considering the small optimized thickness for the freezer as well as the scars.

\section{Problem Geometry Description}

The freezer compartment for no-frost refrigerators shown in Figure 1 (a) and (b) is sketched using the SOLIDWORKS 19 software which sets the key (in centimetres) elliptical scars distributed linearly In the direction of the width and the depth directions, the variation of the spacing $(W)$ from $(4.0 \mathrm{~cm}$ $6.0 \mathrm{~cm})$ as well as the height of the scar $(\mathrm{H})$ ranges from $(0.5 \mathrm{~cm}-1.0 \mathrm{~cm})$, with the axial fan powered by the AC attachment at the end of the freezer having (5) twisted blades, respectively.

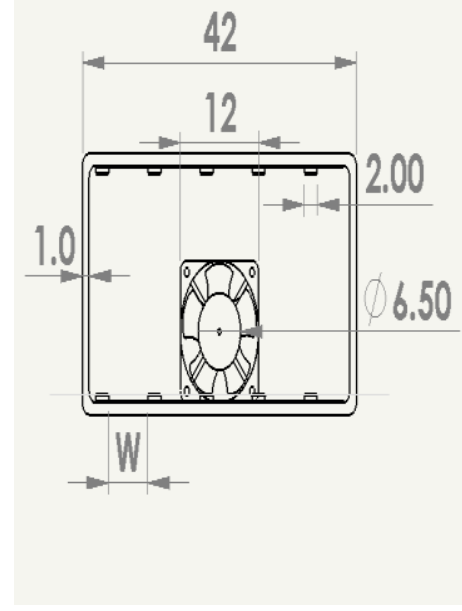

(a) The front and side views

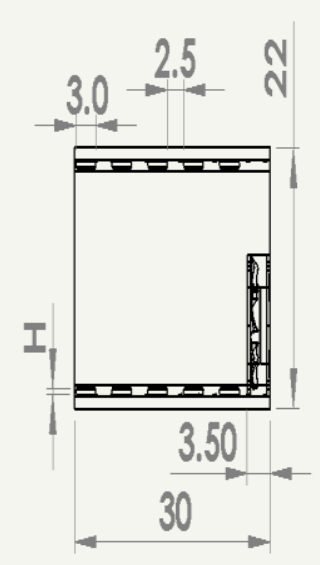

Fig. 1. The freezer compartment geometry

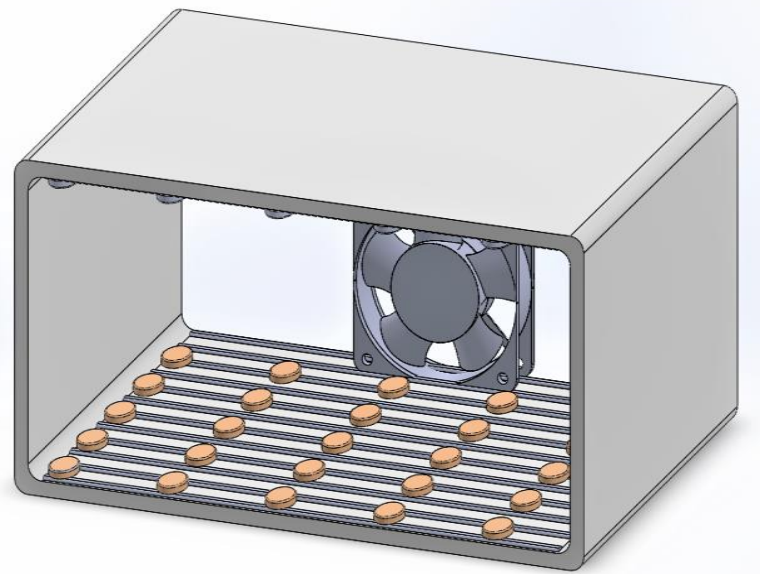

(b) The Isometric view

\section{Methodology}

\subsection{Numerical Technique}

The most commonly used turbulence technique for moving boundary cases involving the integration of the boundary layer is the model of shear stress turbulence (SST) which has obtained the highest precision and consistency of the solution iteration especially for the moving boundary simulation cases, with two equations governing it 
$\frac{\partial}{\partial t}(\rho K)+\frac{\partial}{\partial x}(\rho u K)=\frac{\partial}{\partial x}\left[A_{k} \frac{\partial K}{\partial x}\right]+B_{K}-Y_{K}+S_{K}$

$\frac{\partial}{\partial t}(\rho \omega)+\frac{\partial}{\partial x}(\rho u \omega)=\frac{\partial}{\partial x}\left[A_{\omega} \frac{\partial \omega}{\partial x}\right]+B_{\omega}-Y_{\omega}+S_{\omega}$

Where the terms $\left(A_{k, w}\right.$ and $\left.B_{k, w}\right)$ represents the turbulence diffusivity of both of the kinetic energy and the its rate of dissipation and also the rate of their generation rates.

In order to achieve the numerical solution conservation target within (1e-4) as the mean residual error for the continuity, the Navier-Stokes and the energy equations, the transient second-order backward Euler approach is considered with setting the high-resolution option for both of the turbulence and the advection schemes, respectively.

In order to activate the interference between the rotational solid fan and the static airflow, the displacement mesh formation is adopted for the numerical turbulent flow solution that is increased by a constant exponent of (2) near the small cells volumes (including the fan blades) with respect to the initial time iteration composed mesh. Moreover, the general connectional interface between the two domains is adopted assuming the non-slipping wall condition for the momentum and continuity solving. In addition, the fan rotated air domain velocity near the wall's boundary is evaluated with respect to the global z-direction rotational mesh.

The system and consistency of mesh is one of the major concerns in the solution. The automated meshing option is selected by following the ANSYS CFX taking into account the curvature form size feature with the option of a smooth transition inflation and the introduction of a linear elements type form defining maximum layers to (5) with the default transition of (0.77) and (1.2) growth rates, The CFX had automatically set the tetrahedron preference which resulted in excess mesh consistency reaching 1650000 nodes and 8800000 cells which, in addition to the fan body and blades in addition to the scars walls are concentrated at the flow area closed to them as shown in the Figure $2(\mathrm{a})$ and (b) as below.

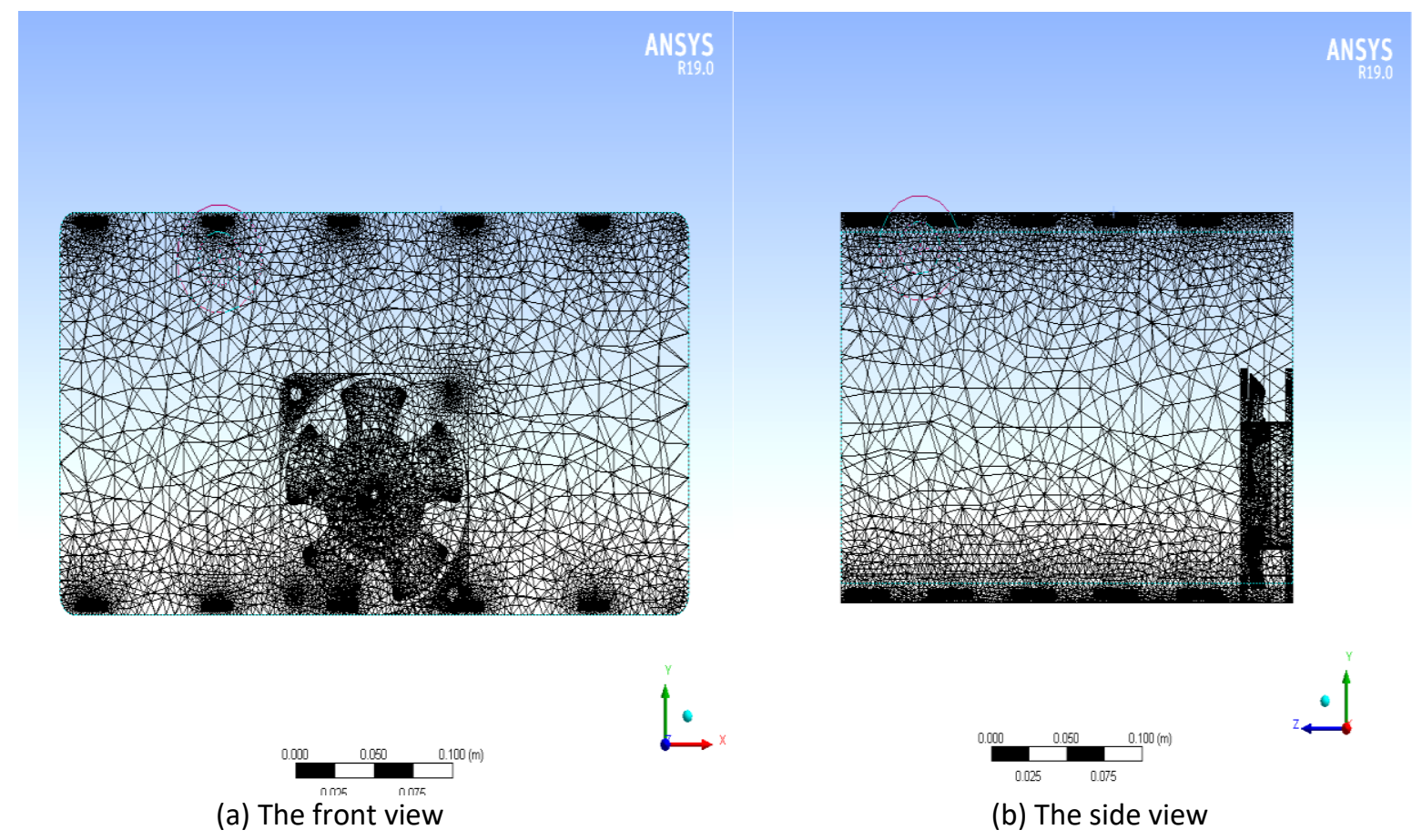

Fig. 2. The simulation case configured mesh in span and depth directions 
By setting the time stage to $(0.25)$ seconds for a total time, the transient case $(15,20 \& 25)$ seconds representing the traveling boundary axial ventilator as the rotational stable domain and selecting mesh deformation for specified motion regions relative to the original deformed mesh. The general method of linking interface between the flow and the solid domain is managed to accomplish the CFX settings.

\subsection{Estimated Boundary Conditions}

Until setting the fluid domain boundary conditions, the measured measurements data must be introduced for the temperature values from the start of the refrigerator process until the cooled air pressure is reached near the walls of the container. Subsequent limits apply

i. Through modeling, the fan default rotational velocity (1500) rpm is assumed to be constant, the

freezer compartment is viewed as an ambient opening form boundary exposed to (30) ${ }^{\circ} \mathrm{C}$ an d setting atmospheric pressure surrounding air.

ii. Since the top wall temperature of the evaporator compartment is influenced by the Refrigerant internal tubing flow, the lowest temperature setting value for the simulation is assumed, the illustrated Table 1. indicates the pre-selected B.C.

Table 1

Estimated Boundary conditions (after 5 minutes of Refrigerator operation)

\begin{tabular}{ll}
\hline Wall definition & Temperature, ${ }^{\circ} \mathrm{C}$ \\
\hline Upper & -5 \\
Right and left & 0 \\
Lower & 0 \\
Upper & -5 \\
\hline
\end{tabular}

\subsection{Experimental Arrangement}

Using (50) pieces of hard plastic material elliptical scars with a height of $(0.5 \mathrm{~cm})$ created via the 3D printing system, the no-frost refrigerator freezer modifications are carried out That was equally sticky to the upper and lower inner surfaces of the freezer as shown in Figure 3 with positioning the axial fan at the end of the freezer compartment with linear gap gaps $(4 * 2.5) \mathrm{cm}$ between each scar.

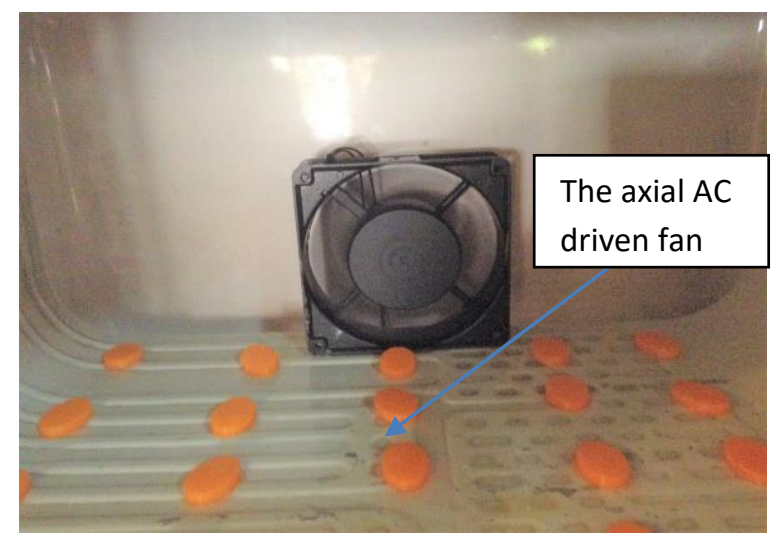

Fig. 3. The freezer modification with the inserted elliptical scars and the axial fan 
A small portable velocity-temperature digital anemometer is used in the reading of the air properties as shown in Figure 4 to measure the desired air domain properties including rotational velocity and static temperature throughout the freezer compartment. This device operates within the temperature and velocity ranges between $(0-50 \circ \mathrm{C})$ and $(0.4-30 \mathrm{~m} / \mathrm{sec})$ and its reading resolution within (0.1) for the two quantities and accuracy of about $( \pm 0.8 \circ \mathrm{C})$ and $( \pm 0.03-0.04 \mathrm{~m} / \mathrm{sec})$, respectively.

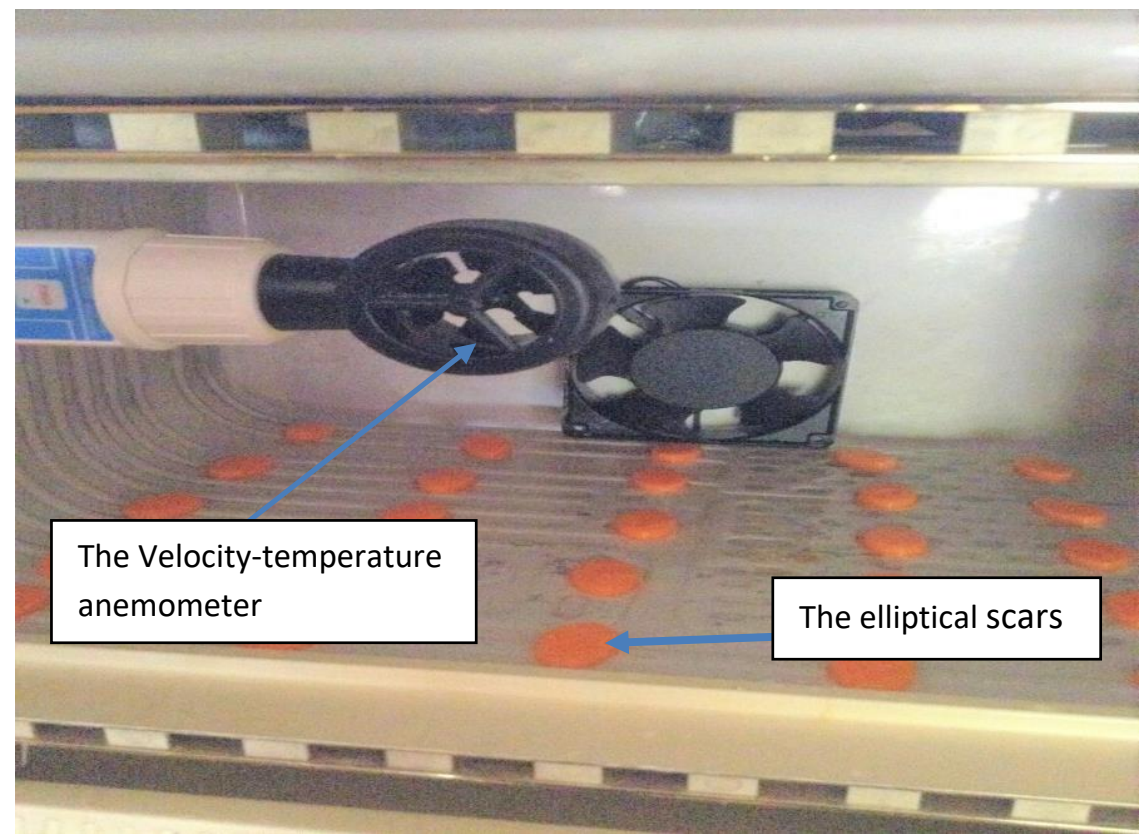

Fig. 4. The utilized velocity-temperature anemometer for the circulated air properties reading

\section{Results and Discussion}

In order to distinguish that the generated mesh consistency represents the maximum permeable account that the simulation results are not affected. Two comparative simulation runs are performed for the adopted and the further condensed mesh grid exceeds 180000 and 94000000 in number of nodes and cells for the freezer cabinet with attached case (2) scars as an example. The variation in the temperature contour for both of the utilized mesh shows a small portion of temperature variation that does not exceeds (0.2\%) within the domain as indicated in Figure 5 (a) and (b). This led to the adoption of the prescribed mesh of 1650000 and 88000000 as the optimum grid characteristics.

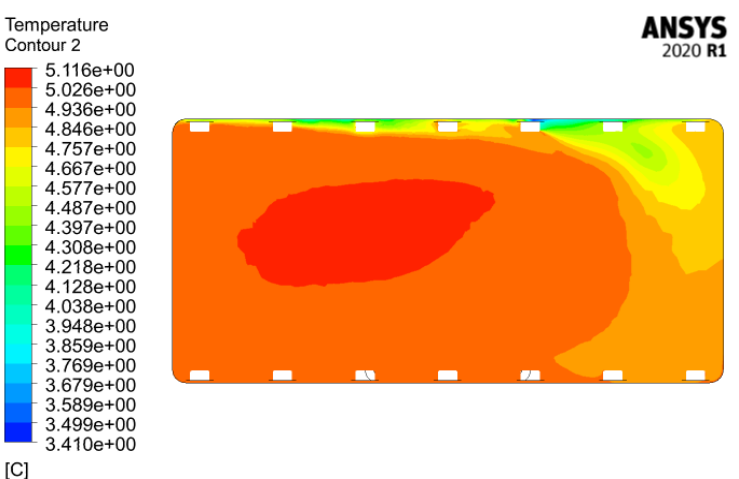

(a) The $1^{\text {st }}$ mesh

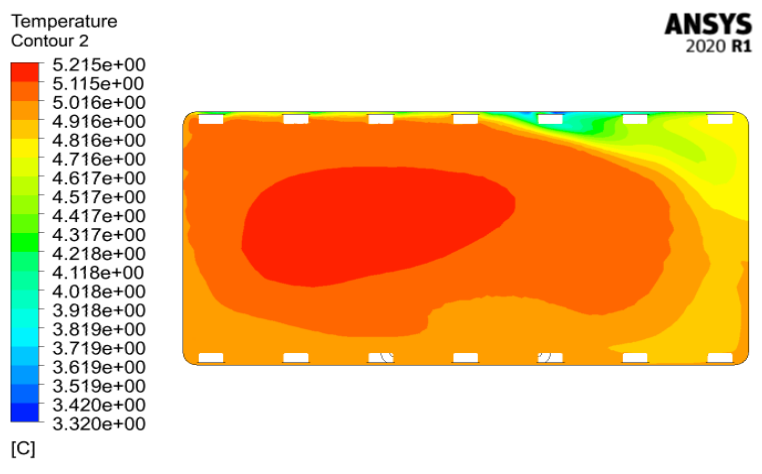

(b) The $2^{\text {nd }}$ mesh

Fig. 5. Grid independency test results comparison 
For the study of the effect of the mounted scars on the flow domain in the presence of an axial fan, three comparisons are conducted according to the method of distribution outlined in Table 2.

Table 2

Adopted cases for simulation

\begin{tabular}{ll}
\hline Case & Dimensional characteristics \\
\hline No scars & None \\
Scars (1) & $6 \mathrm{~cm}$ longitudianl gap \\
& $2.5 \mathrm{~cm}$ depth wise gap \\
& $0.5 \mathrm{~cm}$ in height \\
Scars (2) & $4 \mathrm{~cm}$ longitudianl gap \\
& $2.5 \mathrm{~cm}$ depth wise gap \\
& $0.5 \mathrm{~cm}$ in height \\
Scars (3) & $4 \mathrm{~cm}$ longitudianl gap \\
& $2.5 \mathrm{~cm}$ depth wise gap \\
& $1 \mathrm{~cm}$ in height \\
\hline
\end{tabular}

\subsection{Validation of the Results}

The outlined Figures 6 and 7 Shows a comparison of average numerical solution tests for air temperature and velocity values at the middle of the freezer along the course of the freezer depth with the data collected from the anemometer velocity-temperature readings for selected case scars (1), respectively. The figures show that the average percentage loss for the temperature does not surpass (14\%) and for the air velocity is (7\%).

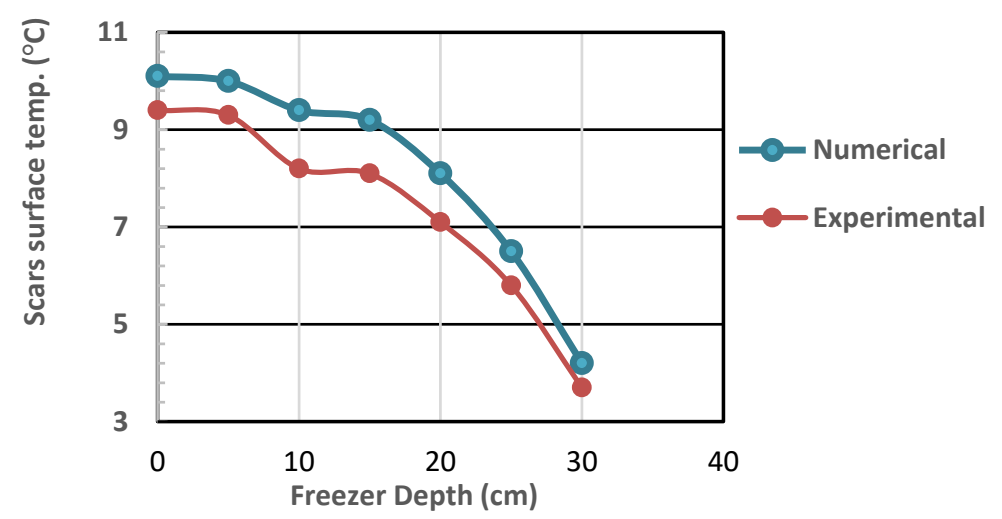

Fig. 6. comparison of numerical and experimental temperature of air for case (1)

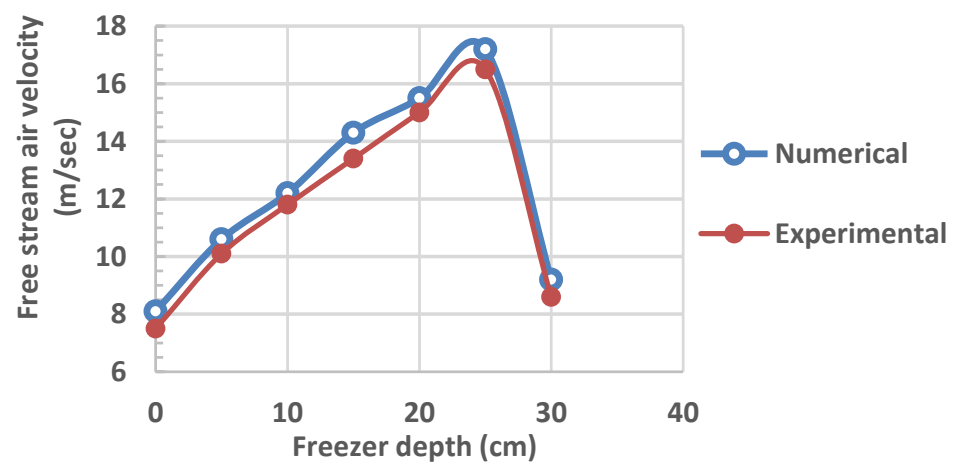

Fig. 7. Comparison of numerical and experimental velocity of air for case (1) 


\subsection{The Velocity Streamlines Variation}

As seen from Figures 8 and 9 representing the air domain in the original and the attached scars of case (1) dimensions freezer as illustrated in Table 2 taking into account the constant rotational fan, a slightly flow acceleration is occurred between the freezer edges and the fan hub as shown in Figure 8.

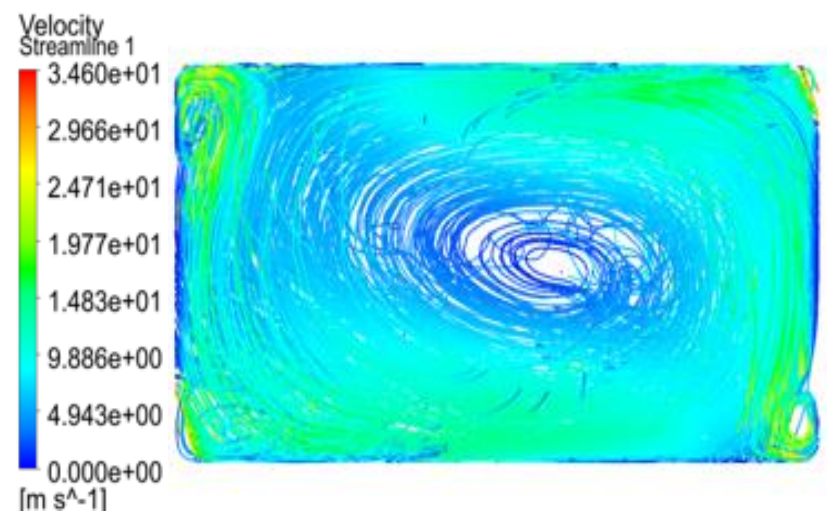

Fig. 8. The circulated domain velocity streamlines with no scars

When attaching the selected scars, a slightly circulated air improvement is obtained in the upper freezer section in addition to the freezer corners as observed in Figure 9 due to the narrowing effect of the cabinet.

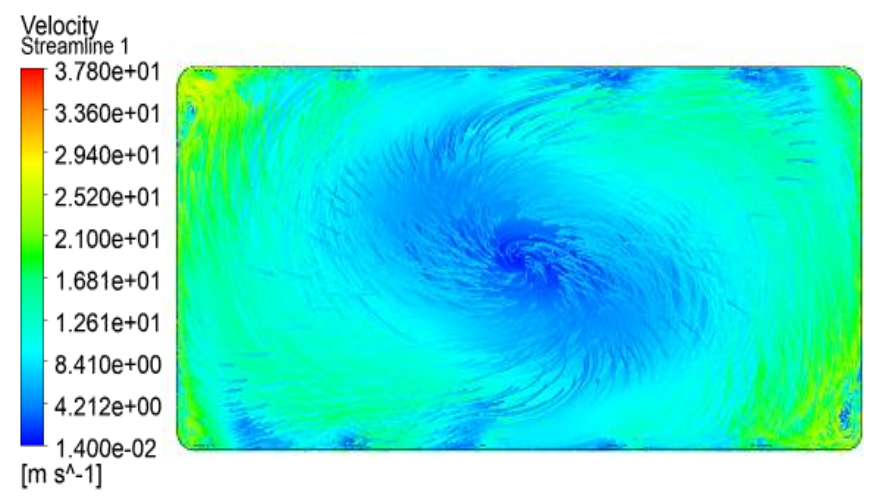

Fig. 9. The circulated domain velocity streamlines for case (1) scars

In order to distinguish the local flow field characteristics within the attached scars gaps in both of the longitudinal width direction, the attachment of the scars with increased height with more converged gap between each row according to the adopted case (2) dimensions increases the flow disturbances between each scar in the middle of the freezer width and within the scars neighboring region as shown in Figure 10 regarding the local differences between the upper and low flow fields acceleration due to the fan localization attached at the freezer lower surface which will produce a locally accelerated flow within the lower surface that is spreading with a non-uniform manner while the upper wall surrounding flow domain is uniformly spreading with gradual acceleration. 


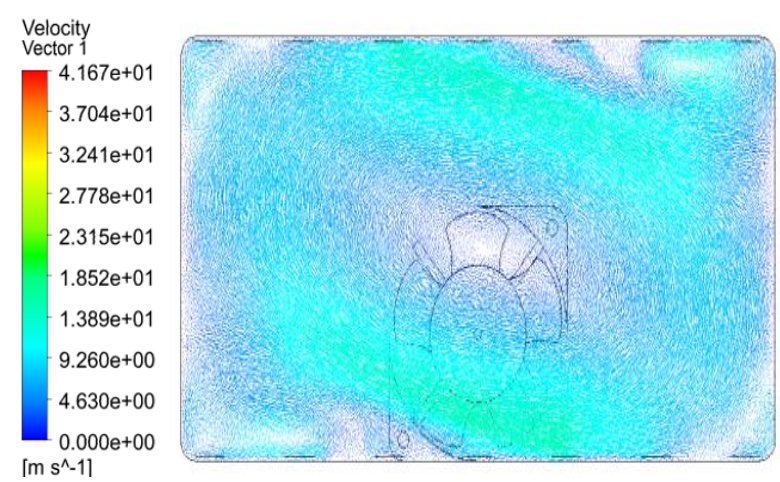

Fig. 10. The front view velocity distribution for case (2) scars

A similar acceleration flow pattern is focused in the freezer depth wise direction as shown in Figure 11 noticing the impact of the rotated flow adjacent to the first-row lower surface scars that are forming an impact surface contributing in the improvement in the rate of circulated air within the compartment.

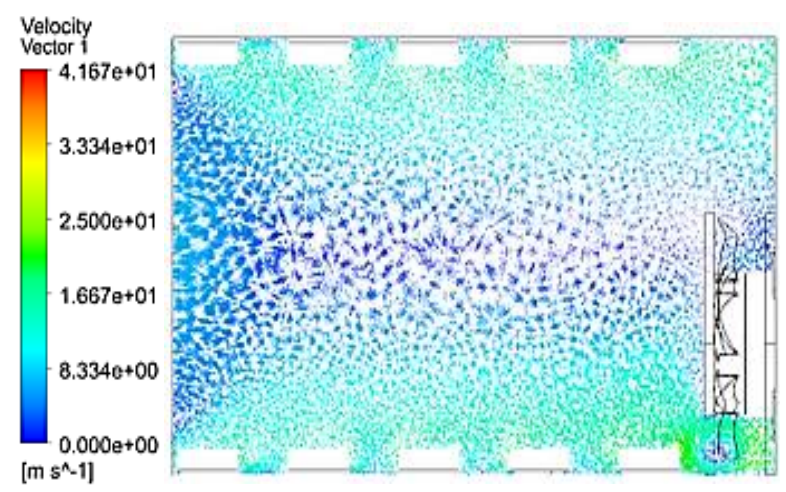

Fig. 11. The side view velocity distribution for case

(2) scars

The flow acceleration pattern at the center-depth location between the more increased height attached scars in Figure 12 shows the highly uniformity axisymmetric condition for the flow domain.

In the depth wise direction, a moderate slope with decreased thickness of accelerated flow above the freezer lower surface is formed as observed in Figure 13 while it remains nearly constant for the upper side section which will lead to conclude that the attaching the scars at the upper wall surface affect the heat transfer by a relatively higher rate than the lower surface depending on the scars characteristic dimensions.

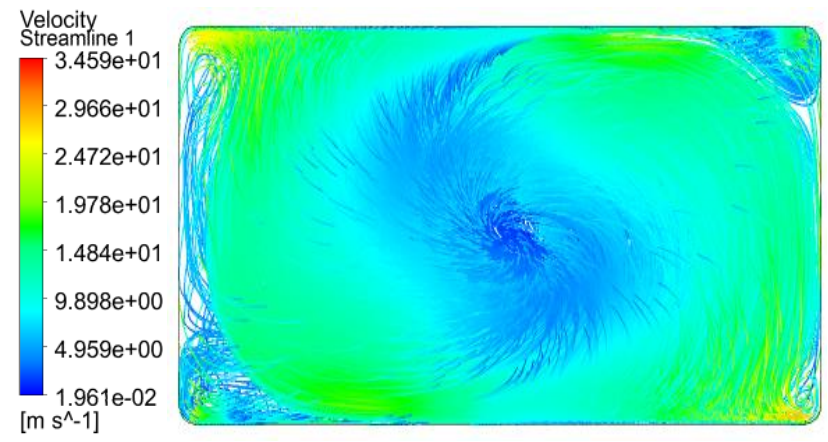

Fig. 12. The circulated domain rotational velocity for case (3) scars 


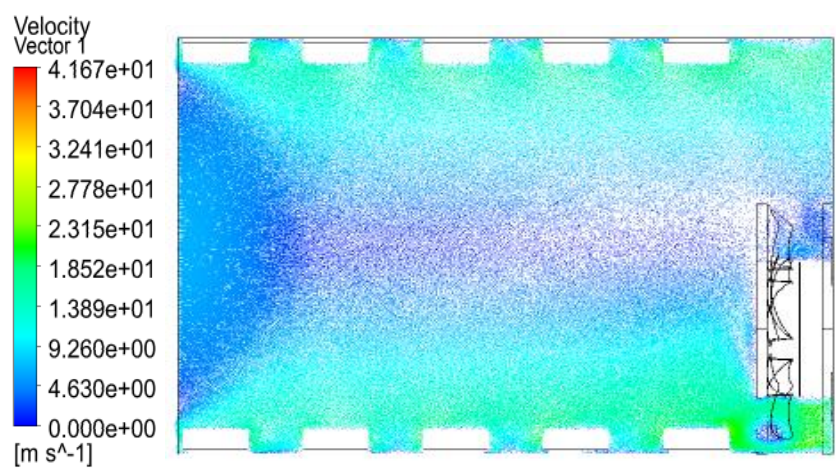

Fig. 13. The circulated domain velocity streamlines for case (3) scars

\subsection{The Temperature Contours Variation}

As the transient case for non-scars freezer is adopted for total time of $(15,20 \& 25)$ seconds in comparison to the scars adopted cases $(1,2 \& 3)$, the following Figure 14 demonstrates the gradual drop down in the quasi-axisymmetric temperature distribution for the original freezer over the same specified time period at the mid-freezer depth view noting that the forced convection utilization serves in the slightly lower freezer cooled contours.

As the time is further elapsed, an improved cooling occurs at the freezer upper wall in the addition to the hot air layers regression toward the lower freezer exit as detected in Figure 15.

When inserting the smallest size of scars for the same time period, two different subcooled regions are formed near both of the freezer walls as indicated in Figure 16; a concentrated subcooled region near the fan due to the relatively accumulated flow layers within this region that diminishes rapidly across the domain, and a thin uniform layer of cold air exists near the freezer upper wall between each scar noticing that its maximum thickness is vertically oriented above the fan rotor.

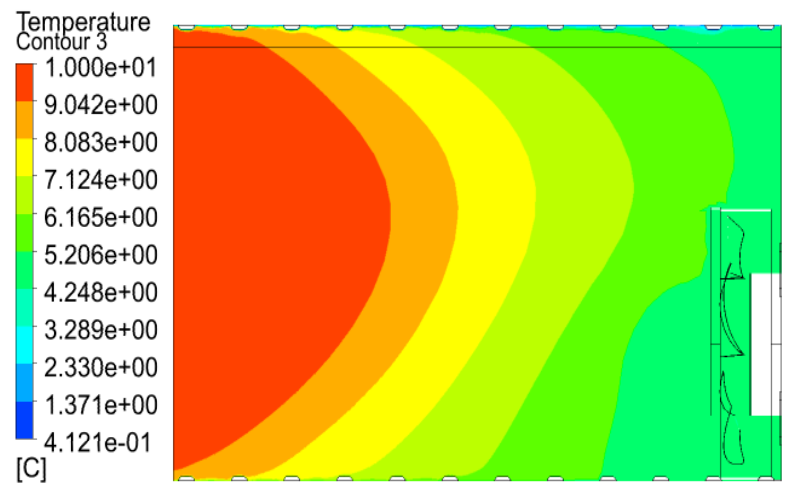

Fig. 14. The air temperature front view at $\mathrm{t}=15 \mathrm{sec}$ for the original freezer 


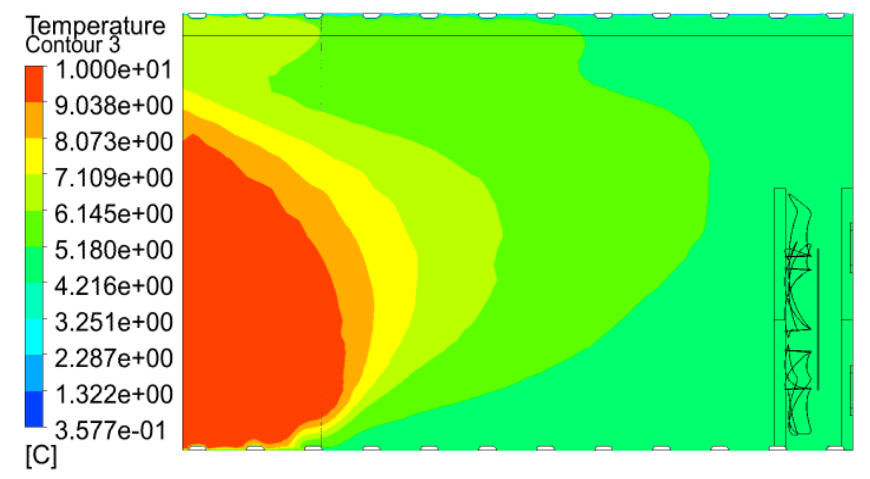

Fig. 15. The air temperature front view at $\mathrm{t}=20 \mathrm{sec}$ for the original freezer

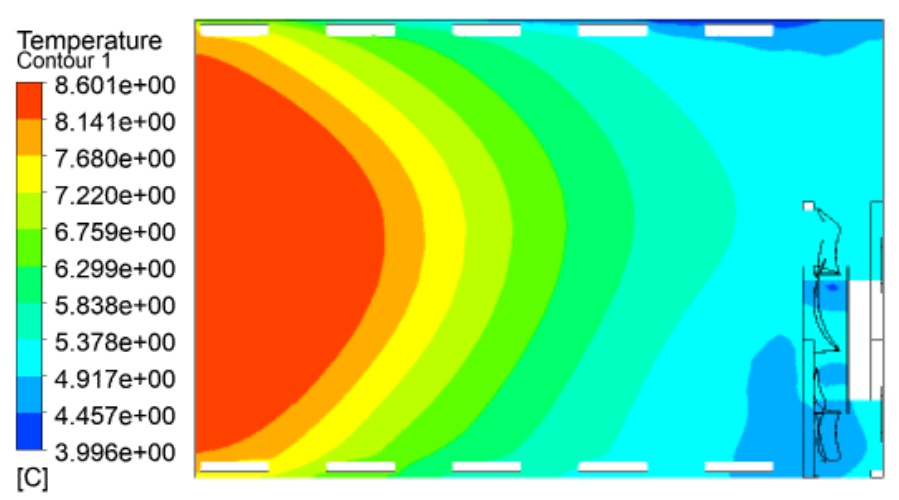

Fig. 16. The air temperature distribution side view at $t=15$ sec for case (1) scars

This local accelerated regions after time elapsed (20) is transferred into a globally curved cold layer throughout the freezer height with sequential rate of climb remarking the local reduction in the maximum level of freezer temperature in the upper left corner adjacent to the freezer ambientexposed flow as a result for the mean difference between the air circulation between the upper and lower surfaces as indicated in Figure 17.

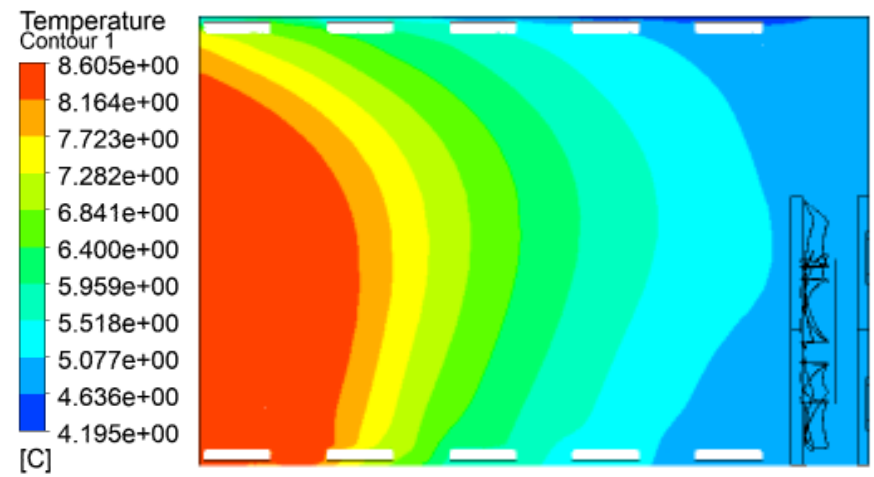

Fig. 17. The air temperature side view at $\mathrm{t}=20 \mathrm{sec}$ for case (1) scars

The transient simulation for the attached scars case (2) dimensions denotes the progressive enhancement in the freezer subcooling and the similar cooling pattern within the scars gaps as shown in Figure 18 noticing the enhanced cooling near the upper wall's scars. 


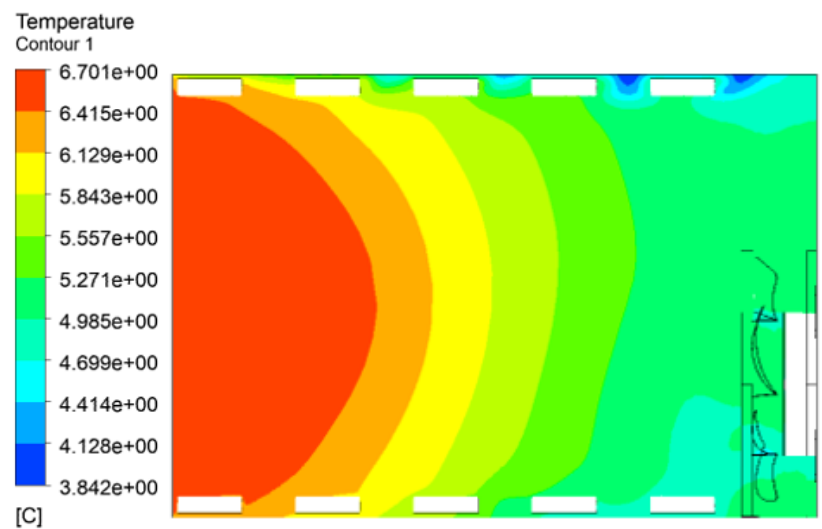

Fig. 18. The air temperature distribution side view at $\mathrm{t}=15 \mathrm{sec}$ for case $(2)$ scars

As the time of simulation is increased to $(20 \mathrm{sec})$, an obviously increased cooling effect is resulted in the upper freezer part located after the fan rotor that is sequenced until reaching the freezer exit compartment as observed in Figure 19 denoting the increased positive effect of the modified scars for the heat transfer enhancement.

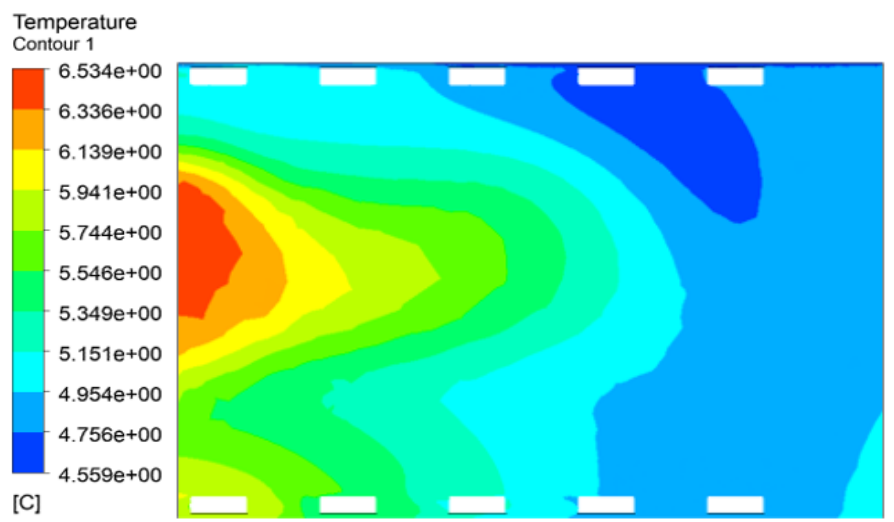

Fig. 19. The air temperature distribution side view at $\mathrm{t}=20 \mathrm{sec}$ for case $(2)$ scars

Further scars modification to the selected case (3) dimensions did not achieve the same subcooling effect especially near the freezer exit as noticed in Figures 20 and 21. Meanwhile, a freezing region is developed at the freezer depth that is traversing slowly with time leading that this utilized scars will further improve the cooling process with more elapsed time to undergo.

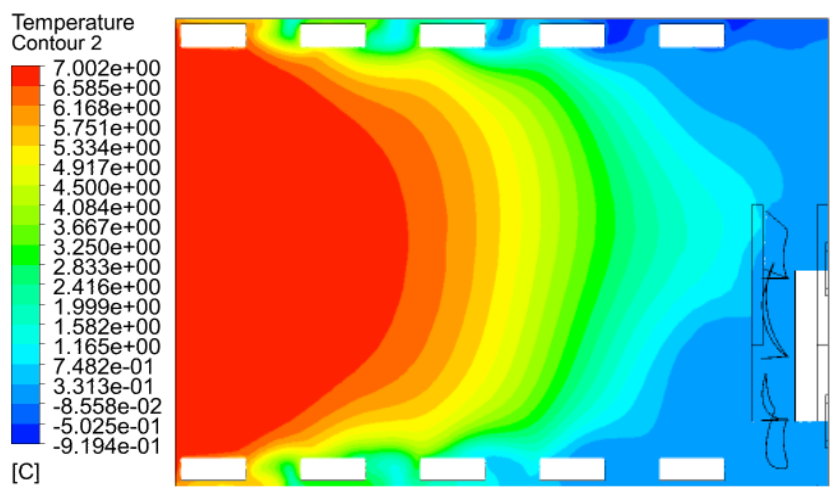

Fig. 20. The air temperature distribution side view at $t=15 \mathrm{sec}$ for case (3) scars 
A second remarking note from Figure 21 shows a small privileged for better air cooling at the upper section of the freezer with more uniform slope for the temperature gradient along the depth wise direction.

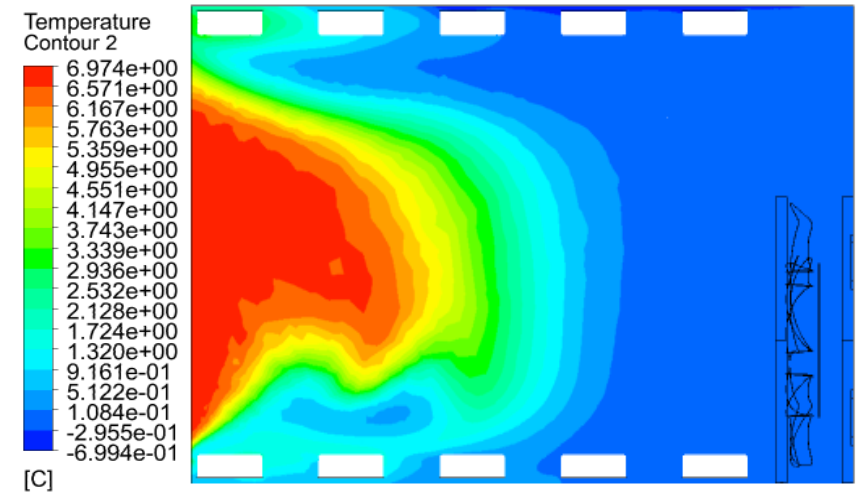

Fig. 21. The air temperature distribution side view at $t=20$ sec for case (3) scars

In the freezer longitudinal direction, the non-scars transient temperature variation shown in Figures $22 \& 23$ shows first a diagonal temperature contours on both of the left-upper and the rightlower corners due to the fan twisting blades profile effect as observed in Figure 22.

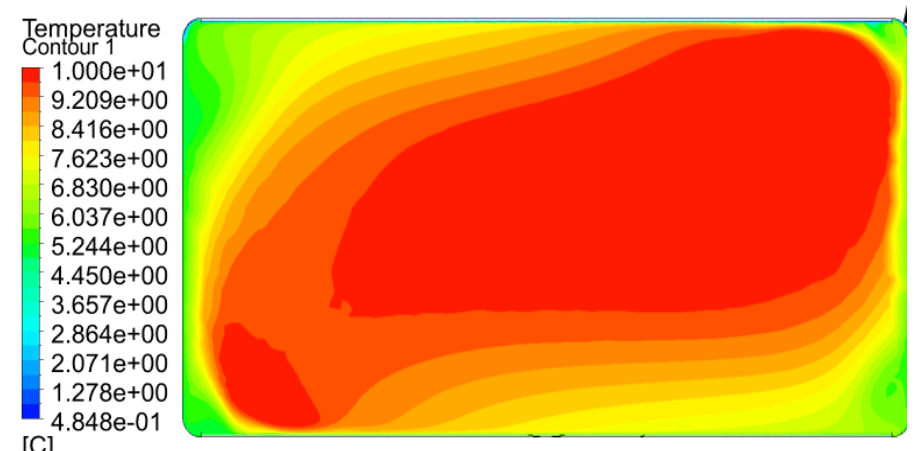

Fig. 22. The air temperature distribution at $\mathrm{t}=15 \mathrm{sec}$ with no scars

When the elapsed time is increased, the sequential approaching to the axisymmetric temperature contours within the flow field is observed from Figure 23 taking into consideration the arbitrary choice for the temperature contour location.

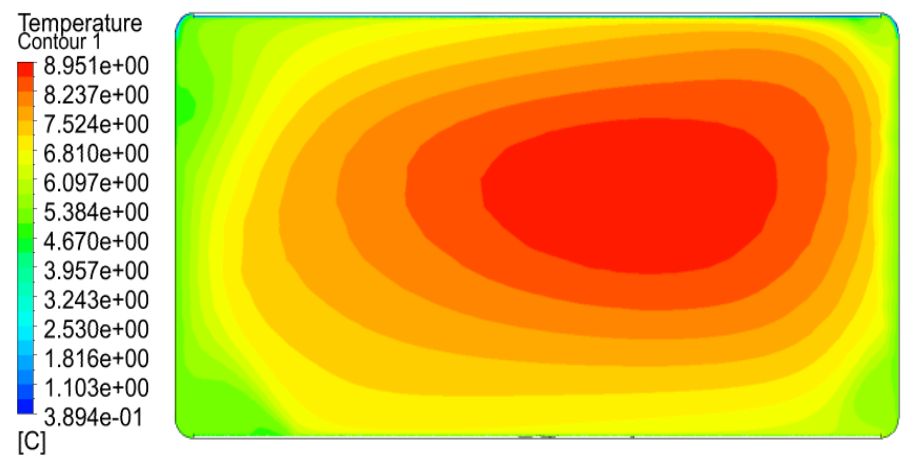

Fig. 23. The air temperature distribution at $\mathrm{t}=20 \mathrm{sec}$ with no scars 
The temperature variability becomes more important in the longitudinal vision when installing the scars, the increase in the height variation of the scars from $(0.5-1.0 \mathrm{~cm})$ in different locations as depicted in Figures 24-29 shows first the more increased diagonal cooling in the temperature contours reaching the axisymmetric diagonal profiles for the domain as shown in Figure 24 .

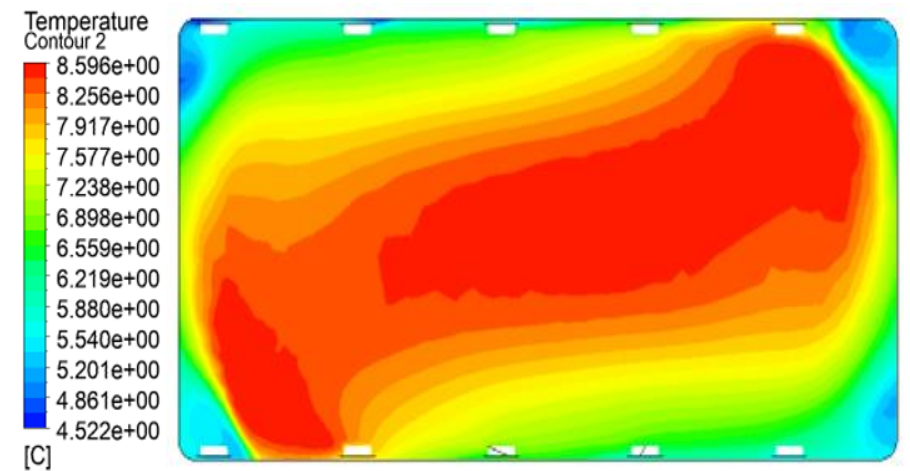

Fig. 24. The air temperature distribution front view at $\mathrm{t}=15 \mathrm{sec}$ for case (1) scars

With further elapsed time, this state starts to diminishes regarding that a small cold sublayer is forming near the upper wall scars region and spreading circumferentially to the downward until reaching the fan propeller location then it is mixed with the center flow region to deform a moderate cold air layer near the freezer lower surface as shown in Figure 25.

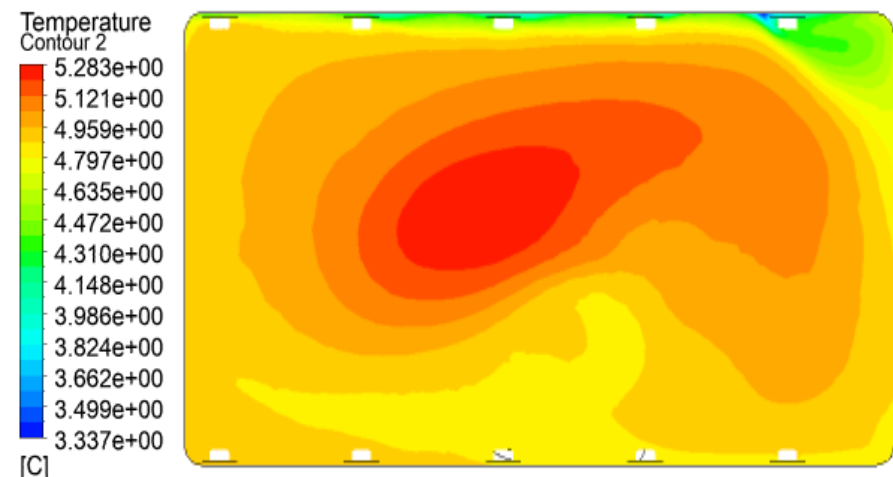

Fig. 25. The air temperature distribution front view at $\mathrm{t}=25 \mathrm{sec}$ for case (1) scars

Further modification of the utilized scars will produce a circulating cooling domain from the upper to the lower section of the freezer as observed in Figure 26 in addition to the absence of the uniformly diagonal temperature variation due to the flow circulation increased resistance imposed by the scars raised height that is concentrated at the freezer lower part.

When the total time of simulation reaches $(25 \mathrm{sec})$, the resulted thin layer of cold flow in the upward section is spreading with relatively higher density downward and forming a more stable temperature contour within the domain as noticed form Figure 27. 


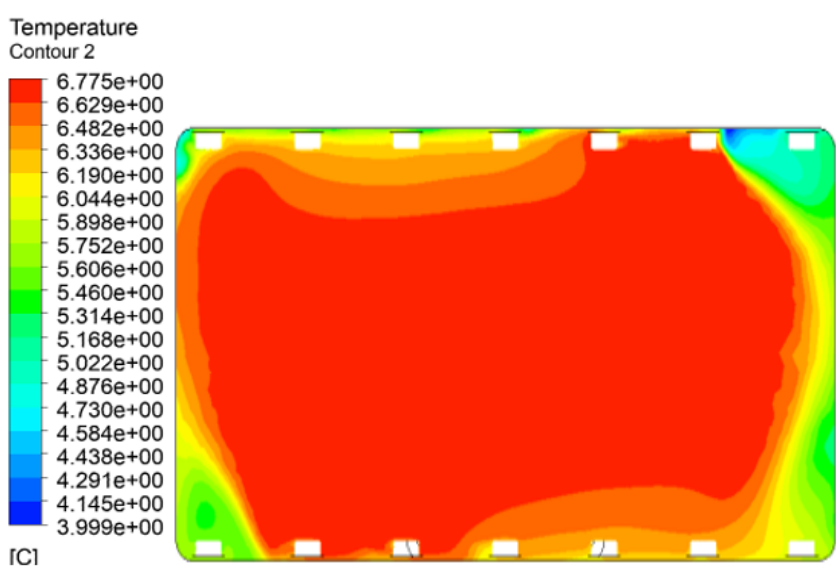

Fig. 26. The air temperature distribution front view at $\mathrm{t}=15 \mathrm{sec}$ for case (2) scars

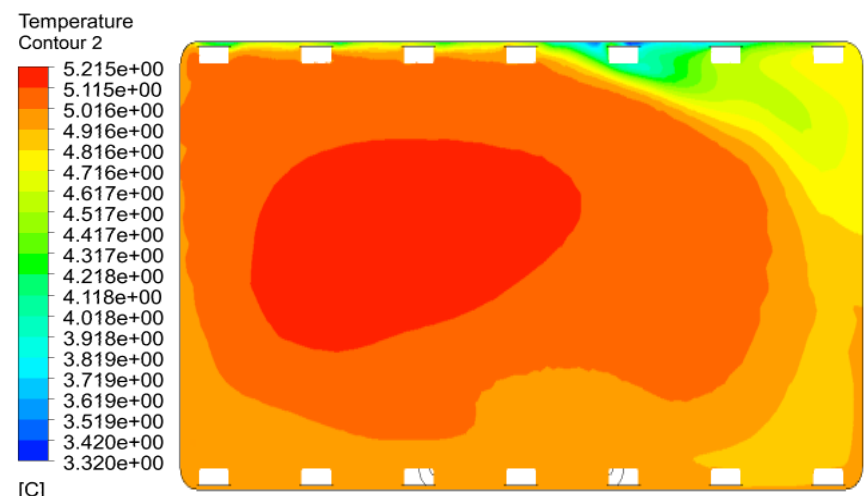

Fig. 27. The air temperature distribution front view at $t=25$ sec for case (2) scars

As the attached scars height is increased to $(1 \mathrm{~cm})$, a below freezing regions are formed near the corners with the formation of semi-oval temperature gradient towards the centre as shown in Figure 28.

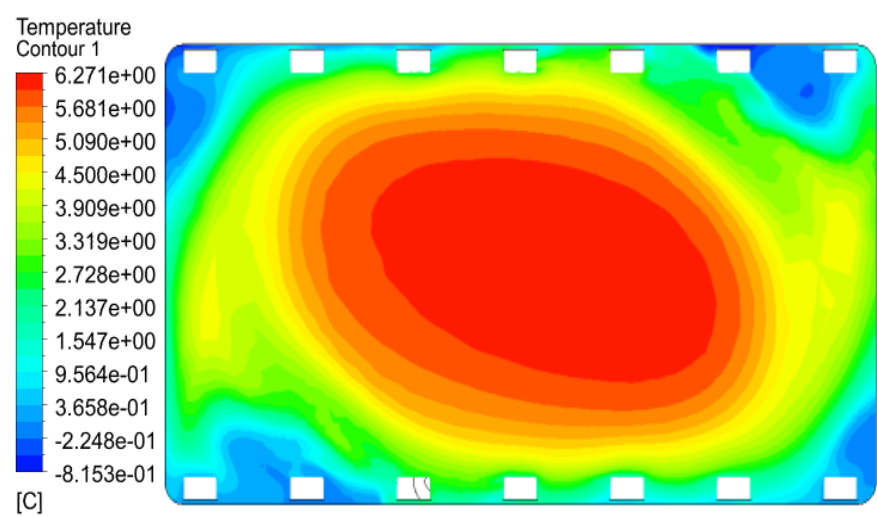

Fig. 28. The air temperature distribution front view at $\mathrm{t}=15 \mathrm{sec}$ for case (3) scars

This tendency in the temperature distribution pattern with more elapsed time will contribute in establishing a uniform cold swirling flow benefiting from the local subcooled spreading flow within the upper wall scars gaps as presented in Figure 29. 


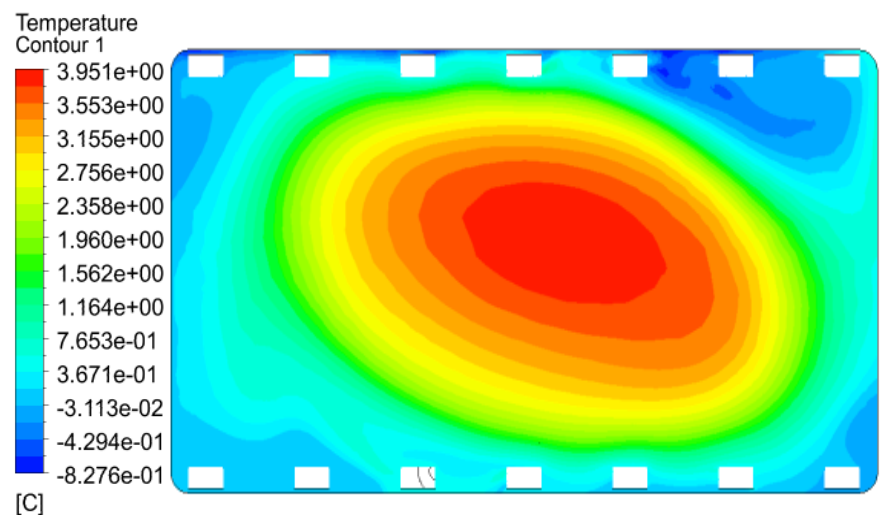

Fig. 29. The air temperature distribution front view at $t=25$ sec for case (3) scars

\subsection{The Wall Heat Transfer Coefficient}

The added Figures 30-34 explain the variability of the air convectional heat transfer coefficient near the upper freezer wall surfaces with / without addition of scars. Figure 30 shows the nonmodified freezer heat transfer coefficient noticing that its maximum value region is close to the surrounding ambient air in addition to the Refrigerant inlet flow to the evaporator while its minimum value is restricted to the freezer side edges.

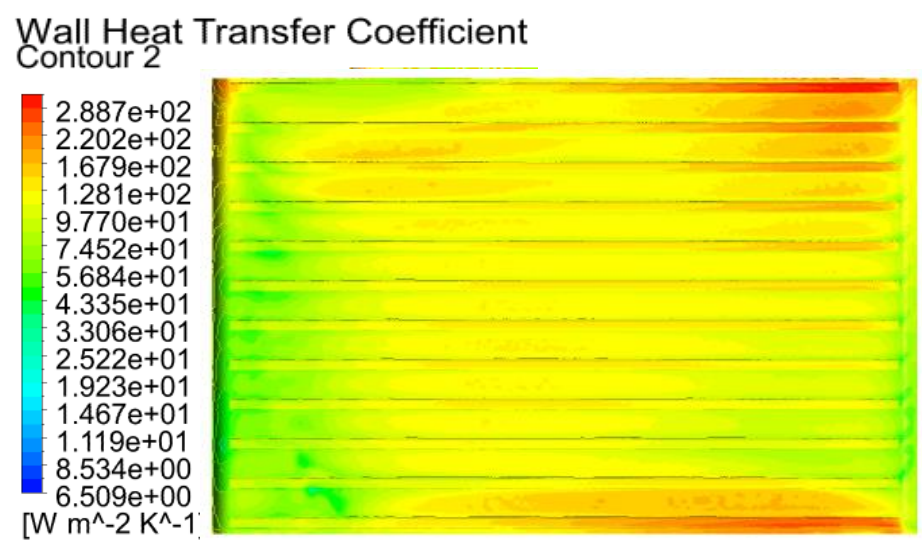

Fig. 30. The wall heat transfer coefficient near the upper surface with no scars

It is clear that the scars relation led by varying degrees to the heat transfer rise denoting that the fluid flow layers near the edges of the scar surfaces have stronger convection heat transfer due to the movement of air layers between each scar as shown in Figure 31 noting that the convection heat transfer gain is much smaller than the previously confirmed value (3.2 percent) denoting that the heat transfer rate is progressively enhancing with elapsing time until reaching the steady state condition.

This fact is confirmed as the elapsed time of simulation is increased to $(20 \mathrm{sec})$ with further improvement in the heat transfer coefficient especially in the mid-core of the freezer starting from the fan location (at the lower middle side) as denoted from Figure 32. 


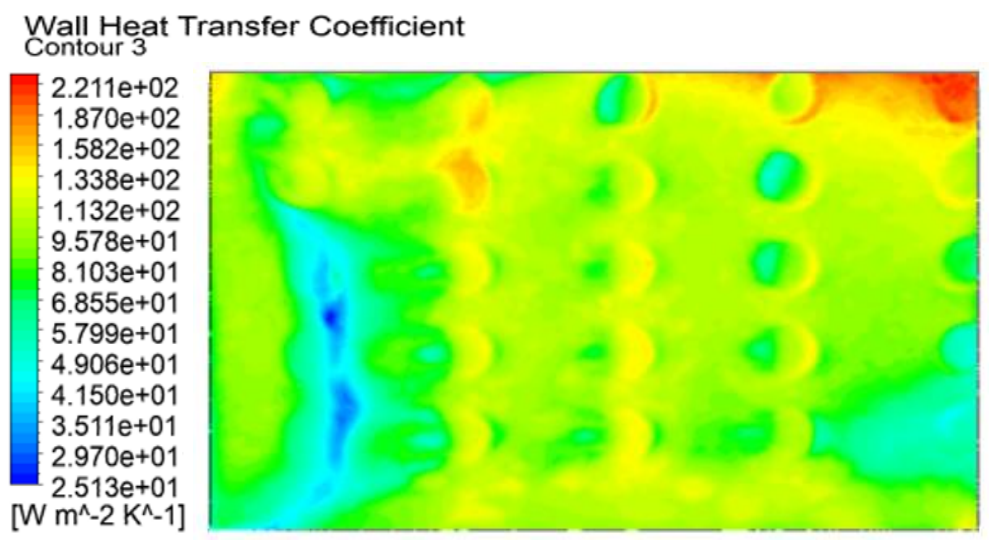

Fig. 31. The wall heat transfer coefficient near the upper surface at $t=15$ sec for case (1) scars

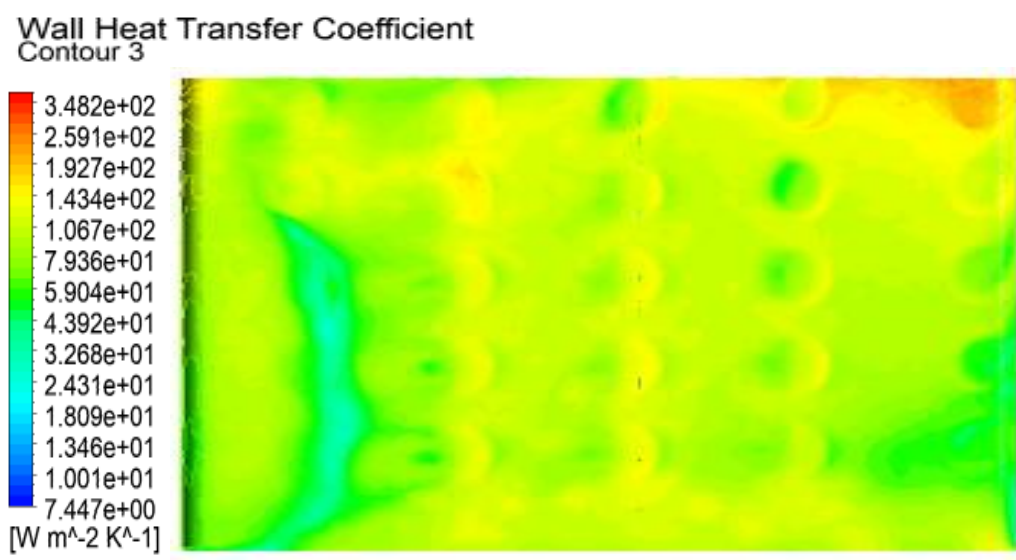

Fig. 32. The wall heat transfer coefficient near the upper surface at $\mathrm{t}=\mathbf{2 0}$ sec for case (1) scars

As noticed from Figure 33 where the utilized scars gap in the longitudinal direction is decreased from $(4-2.5 \mathrm{~cm})$, a slight improvement in the heat transfer coefficient is detected near the scars surfaces in addition to the freezer sides while it is reduced in the gaps region denoting that the gap changing is a quite sensitive parameter that should be investigated furtherly in the outcoming researches.

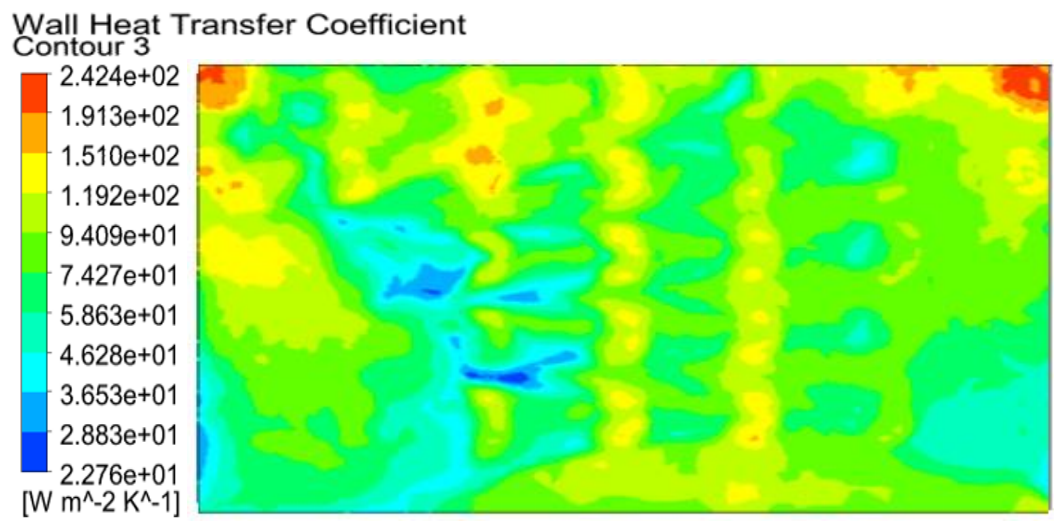

Fig. 33. The wall heat transfer coefficient near the upper surface at $\mathrm{t}=15 \mathrm{sec}$ for case (2) scars 
When the height of the scars is increased $(0.5$ to $1.0 \mathrm{~cm})$, the maximum heat transfer coefficient gained will increase significantly by (12\%) as noticed from Figure 34 . This leads to the conclusion that the scars increased rise represents the most efficient method for enhancing the convection heat transfer in the freezer.

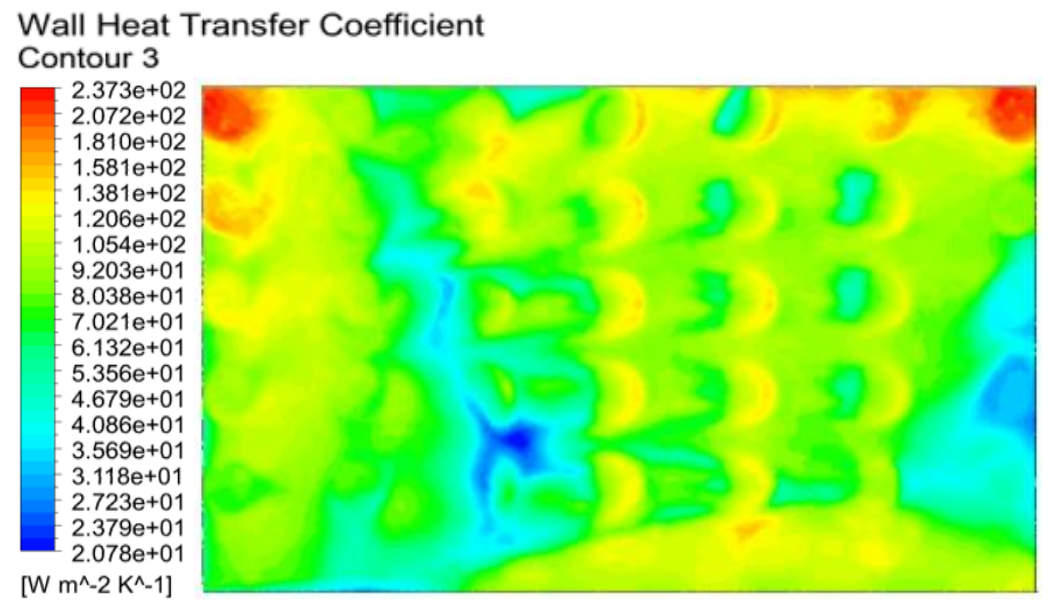

Fig. 34. The wall heat transfer coefficient near the upper surface at $\mathrm{t}=15$ for case (3) scars

\section{Conclusions}

The elliptical form scars incorporating varying gaps and height of scars into the upper and lower inner surfaces of the frost refrigerator freezer compartment have a positive effect on the following circulating air properties

i. The circulation velocity of the internal air is improved instantaneously near the scar's region especially for the lower freezer side.

ii. For the freezer compartment, the more rapid temperature drops and the convection heat transfer coefficeint increasing with the Refrigerator operation time elapsing.

iii. Increasing the scars height with the prediction of the most efficient fan location has the most affecting parameter on improving the heat transfer coefficient of the convection.

iv. In the linear elliptical scars distribution, the reduced gap distance in the longitudinal freezer direction has a negative effect on the heat transfer coefiicent. This parameter sholud be futher investigated for different scars cross-sectional shape with alternative distribution pattern such as the staggered arrangement.

v. The distributed scars at the upper freezer wall improves the heat transfer rate better than the lower surface scars due to their closer location to the evaprator tubing in addition to the installed fan location.

vi. The scars increased height above $(0.5 \mathrm{~cm})$ affect the heat transfer rate in the longitudinal direction other than the depthwise longitudinal direction with remarking a relatively improvement within the upper circulated flow field.

\section{Acknowledgement}

Many thanks to Ass. Prof. Dr. Ahmed A. Mohammed in the Airconditioning and Refrigeration branch for his valuable advice prior to the performing of this work. This research was not funded by any grant. 


\section{References}

[1] Basha, M., and CS Nor Azwadi. "Numerical Study on the Effect of Inclination Angles on Natural Convection in Entrance Region using Regularised Lattice Boltzmann BGK Method." Journal of Advanced Research in Fluid Mechanics and Thermal Sciences 10, no.1 (2015): 11-26.

[2] Krasnoshlykov, Aleksander S., and Vyacheslav I. Maksimov. "Study of natural convection in a freezer at different modes of operation of the refrigeration unit." In EPJ Web of Conferences, vol. 82, p. 01046. EDP Sciences, 2015. https://doi.org/10.1051/epjconf/20158201046

[3] Barbosa Jr, Jader R., Christian JL Hermes, and Claudio Melo. "CFD analysis of tube-fin'no-frost'evaporators." Journal of the Brazilian Society of Mechanical Sciences and Engineering 32, no. 4 (2010): 445-453.

[4] Katkhaw, Nopparat, Nat Vorayos, Tanongkiat Kiatsiriroat, Yottana Khunatorn, Damorn Bunturat, and Atipoang Nuntaphan. "Heat transfer behavior of flat plate having 45 ellipsoidal dimpled surfaces." Case Studies in Thermal Engineering 2 (2014): 67-74.

http://doi.org/10.1016/i.csite.2013.12.002

[5] Chen, Yu, Yong Tian Chew, and Boo Cheong Khoo. "Enhancement of heat transfer in turbulent channel flow over dimpled surface." International Journal of Heat and Mass Transfer 55, no. 25-26 (2012): 8100-8121. http://doi.org/10.1016/i.ijheatmasstransfer.2012.08.043.

[6] Yan, Gang, Qi Chen, and Zhaolei Sun. "Numerical and experimental study on heat transfer characteristic and thermal load of the freezer gasket in frost-free refrigerators." International Journal of Refrigeration 63 (2016): 2536.

https://doi.org/10.1016/j.ijrefrig.2015.10.021

[7] van Campenhout, Olaf W., Michiel van Nesselrooij, Leo L. Veldhuis, Bas van Oudheusden, and Ferry Schrijer. "An experimental investigation into the flow mechanics of dimpled surfaces in turbulent boundary layers." In 2018 AIAA Aerospace Sciences Meeting, p. 2062. 2018.

https://doi.org/10.2514/6.2018-2062

[8] Luo, Lei, Han Yan, Wei Du, Songtao Wang, Changhai Li, and Xinghong Zhang. "Flow structure and heat transfer characteristics of a rectangular channel with pin fins and dimples with different shapes." Journal of Thermal Science and Engineering Applications 11, no. 2 (2019).

https://doi.org/0.1115/1.4041598

[9] Awasarmol, Umesh V., and Ashok T. Pise. "An experimental investigation of natural convection heat transfer enhancement from perforated rectangular fins array at different inclinations." Experimental Thermal and Fluid Science 68 (2015): 145-154.

http://doi.org/10.1016/j.expthermflusci.2015.04.008

[10] Yasin, Nabil Jamil, and Ahmed H. Ghanim. "Assessment for Heat Transfer Enhancement in Heat Exchangers by Using Dimples geometry." Association of Arab Universities Journal of Engineering Sciences 24, no. 2 (2017): 47-63.

[11] Aroonrat, Kanit, and Somchai Wongwises. "Experimental study on two-phase condensation heat transfer and pressure drop of R-134a flowing in a dimpled tube." International Journal of Heat and Mass Transfer 106 (2017): 437-448.

http://doi.org/10.1016/j.ijheatmasstransfer.2016.08.046

[12] Nazari, Saeed, Mahdi Zamani, and Sajad A. Moshizi. "Comparative study on the influence of depth, number and arrangement of dimples on the flow and heat transfer characteristics at turbulent flow regimes." Heat and Mass Transfer 54, no. 9 (2018): 2743-2760. http://doi.org/10.1007/s00231-018-2307-5

[13] Wu, Xuehong, Lihua Feng, Dandan Liu, Hao Meng, and Yanli Lu. "Numerical study on the effect of tube rows on the heat transfer characteristic of dimpled fin." Advances in Mechanical Engineering 6 (2014): 637052. http://doi.org/10.1155/2014/637052

[14] Zhao, Hongxia, F. Zhang, D. Wang, and J. Han. "Enhanced freezing process with finned aluminum plates inside a home refrigerator." In International Heat Transfer Conference Digital Library. Begel House Inc., 2018. http://doi:10.1615/IHTC16.rac.022141

[15] Nikbay, Melike, M. Berkay Acikgoz, and Husnu Kerpicci. "Investigation of Airflow and Temperature Distribution in the Freezer Cabinet of a Domestic No-Frost Refrigerator." In ASME 2009 Heat Transfer Summer Conference collocated with the InterPACKO9 and 3rd Energy Sustainability Conferences, pp. 689-694. American Society of Mechanical Engineers Digital Collection, 2009.

http://doi:10.1115/HT2009-88121

[16] Laguerre, O., S. Ben Amara, J. Moureh, and D. Flick. "Numerical simulation of air flow and heat transfer in domestic refrigerators." Journal of food engineering 81, no. 1 (2007): 144-156.

http://doi:10.1016/j.jfoodeng.2006.10.029 
[17] Lacerda, V. T., C. Melo, J. R. Barbosa Jr, and P. O. O. Duarte. "Measurements of the air flow field in the freezer compartment of a top-mount no-frost refrigerator: the effect of temperature." International journal of refrigeration 28, no. 5 (2005): 774-783.

http://doi:10.1016/i.ijrefrig.2004.10.009

[18] Lee, Jang-Seok, and Kwan-Soo Lee. "Heat transfer performance of evaporator used in a domestic refrigerator/freezer under frosting condition." Korean Journal of Air-Conditioning and Refrigeration Engineering 17, no. 1 (2005): 62-70.

[19] Çerezci, Gökhan, Murat Darka, and Ozan Şenman. "Airshuffler implementation at freezer air outlets for heat transfer enhancement." In AIP Conference Proceedings, vol. 1738, no. 1, p. 030010. AIP Publishing LLC, 2016.

https://doi.org/10.1063/1.4951766

[20] Sommers, A. D., and A. M. Jacobi. "Air-side heat transfer enhancement of a refrigerator evaporator using vortex generation." International journal of refrigeration 28, no. 7 (2005): 1006-1017. http://doi:10.1016/i.ijrefrig.2005.04.003

[21] Lee, Sang Hun, Won Jae Yoon, Yongchan Kim, Mooyeon Lee, and Seongjung Yun. "Study on performance characteristics of spiral fin-tube evaporator applied to domestic refrigerator-freezers." Transactions of the Korean Society of Mechanical Engineers B 37, no. 3 (2013): 205-212. http://doi.org/10.3795/KSME-B.2013.37.3.205

[22] Celik, Serdar, and Emmanuel C. Nsofor. "Performance analysis of a refrigerating system with a grooved-tube evaporator" Applied Thermal Engineering 73 (2014):743-748. http://doi.org/10.1016/i.applthermaleng.2014.08.033

[23] Liu, Guoqiang, Gang Yan, and Jianlin Yu. "Research on test method of heat transfer coefficient for refrigerator gasket." International Journal of Refrigeration 110 (2020): 106-120. https://doi.org/10.1016/i.ijrefrig.2019.11.007 